\title{
Basic Life Support Knowledge, Awareness, and Attitude among Dental Students in Davangere City, Karnataka, India: A Cross-sectional Study
}

\author{
${ }^{1} \mathrm{~A}$ Suma Bindu, ${ }^{2} \mathrm{~V}$ Hirekalmath Sushanth, ${ }^{3} \mathrm{PG}$ Naveen Kumar, ${ }^{4} \mathrm{GM}$ Prashant, ${ }^{5}$ Mohamed Imranulla
}

\begin{abstract}
Introduction: According to the World Health Organization, heart disease is the world's largest killer claiming 17.5 million lives every year. Every 29 seconds, an Indian dies of heart problem. It is important that every member of our community including dental practitioners be trained in high-quality cardiopulmonary resuscitation (CPR) as it is a basic medical skill, which can save many lives if implemented timely.
\end{abstract}

Aim: The aim of the study was to determine basic life support (BLS) knowledge, awareness, and attitude among clinical dental students (III and IV year students), interns, and postgraduate students in the dental colleges of Davangere city, Karnataka, India.

Materials and methods: A cross-sectional study was conducted by using a close-ended, validated questionnaire comprising 17 questions pertaining to demographic details, knowledge, awareness, and attitude toward BLS among clinical dental students in Davangere city. Descriptive, chi-squared test and Logistic regression were used to analyze the data using Statistical Package for the Social Sciences version 20.

Results: After excluding the incomplete response forms, the data were analyzed for 495 responders with a response rate of $96.6 \%$. In the present study, only $23.2 \%$ of the responders answered that the rate of chest compression is $100 /$ minute in adults and children and $62.2 \%$ of the students were not aware of Heimlich maneuver. About $68.5 \%$ students had not attended previous BLS workshops.

Conclusion: The present study highlights that the overall knowledge, awareness, and attitude among dental students regarding BLS is not satisfactory in Davangere. This study emphasizes the fact that undergraduate course in dentistry must be regularly updated on the knowledge and skills regarding BLS along with practical courses.

Keywords: Basic life support, Cross-sectional study, Dental students.

How to cite this article: Bindu AS, Sushanth VH, Kumar PGN, Prashant GM, Imranulla M. Basic Life Support Knowledge, Awareness, and Attitude among Dental Students in Davangere City, Karnataka, India: A Cross-sectional Study. J Oral Health Comm Dent 2017;11(2):23-28.

${ }^{1}$ Postgraduate Student (Final Year), ${ }^{2,5}$ Reader, ${ }^{3}$ Professor and Head, ${ }^{4}$ Professor

${ }^{1-5}$ Department of Public Health Dentistry, College of Dental Sciences, Davangere, Karnataka, India

Corresponding Author: A Suma Bindu, Postgraduate Student (Final Year), Department of Public Health Dentistry, College of Dental Sciences, Davangere, Karnataka, India, Phone: +919591610774, e-mail: adapasumabindu@gmail.com

\section{Source of support: Nil}

Conflict of interest: None

\section{INTRODUCTION}

The life of an individual is influenced by various factors like health, education, occupation, and socioeconomic status. Among these factors, health influences the life of an individual to a great extent. There are systemic conditions like myocardial infarction, congestive cardiac failure, and stroke, which may cause death of an individual. ${ }^{1}$ According to the World Health Organization, cardiac diseases are the world's largest killer claiming 17.5 million lives every year. Every 29 seconds a person dies in India due to cardiac problem. As many as 20,000 new people develop heart disease every day. In India, 90 million suffer from heart disease and more than $30 \%$ are at high risk of sudden cardiac arrest (SCA). ${ }^{2}$

There are different ways by which the occurrence of death of an individual due to cardiac problems may be prevented. They include the instructions given and medications prescribed by health professionals, diet, and physical exercises. In addition to these ways, BLS in case of medical emergencies is most important. The BLS is the provision of treatment designed to maintain adequate circulation and ventilation to the patient in cardiac arrest, without the use of drugs. It includes recognition of signs of SCA, heart attack, stroke and foreign body airway obstruction, and skills of CPR and defibrillation with an automated external defibrillator. ${ }^{3-6}$

The BLS is a core skill in which all health care professionals should be proficient. As health care professionals, dental practitioners also encounter life-threatening medical emergencies in routine practice. ${ }^{7}$ Fear and anxiety within the confines of the dental office due to increased level of stress often may make these patients prone to medical emergencies. Effective management of an emergency situation in the dental office is ultimately the dentist's responsibility. ${ }^{7}$ It is logical to provide BLS training during undergraduate years ensuring basic competence in all graduating health care students. ${ }^{8}$ The literature is limited in regard to the BLS knowledge among dental students in Davangere city, Karnataka, India. With this background, the present study was undertaken to assess 
the knowledge, awareness, and attitude of BLS among undergraduate clinical (III year, IV year, interns) and postgraduate dental students in Davangere city.

\section{MATERIALS AND METHODS}

The present study was a questionnaire-based survey, consisting of 17 questions pertaining to the knowledge, awareness, and attitude toward BLS among dental students in Davangere.

The study was conducted from February to March 2016. The protocol was approved by the Institutional Review Board of College of Dental Sciences with Ref. No. CODS/1015/2016-2017.

All clinical and postgraduate students of two dental colleges in Davangere, who were present on the day of distribution of questionnaire, were included in the study.

Questionnaire was administered to a sample of $15 \mathrm{stu}-$ dents attending public health dentistry clinical posting who were interviewed to gain feedback on the overall acceptability, validity, and reliability of the questionnaire in terms of length, language clarity, time, and feasibility of students completing and returning it. Based on the opinions expressed, a mean content validity ratio of 0.85 was found. After obtaining the consent from each participant, the questionnaire was self-administered by single investigator. Each one was asked to fill the provided questionnaire in front of the investigator with adequate time to avoid any malpractice while answering. Confidentiality was maintained throughout the process. Incomplete response sheets were excluded from data capturing and analysis.

The structured questionnaire consisted of three sections:

1. Demographic data and professional qualification: (name, gender, age, academic level).

2. Knowledge of participants related to BLS (nine closeended questions).

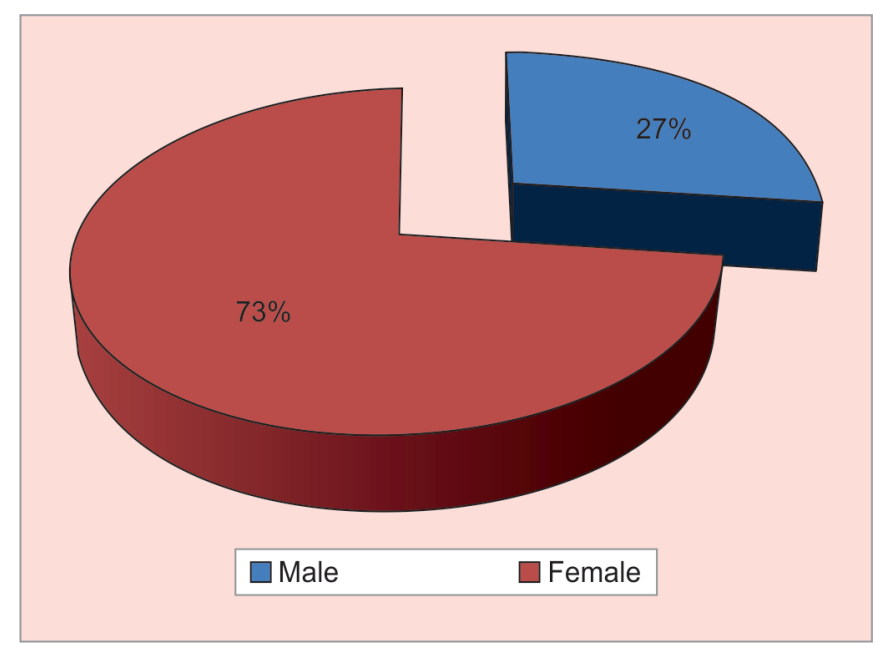

Graph 1: Percentage distribution of students based on their gender
3. Awareness and attitude toward BLS (eight closeended questions).

The answer keys for the core questions on knowledge of BLS were generated using the BLS manual from the American Heart Association. ${ }^{9}$

\section{DATA PROCESSING AND ANALYSIS}

The data from 495 clinical dental students so obtained were entered in Excel sheet, and descriptive and inferential statistical analysis was made. Statistical Package for Social Sciences software version 20.0 was used for data analysis.

The chi-squared test was used to test associations between the responses among the age, genders, qualification, and academic year. Binominal logistic regression analysis was done to compare the knowledge of undergraduates and postgraduates whereas multinominal logistic regression analysis was done to compare the knowledge of IV year students, interns, and postgraduates with reference to III year students. A critical p-value of 0.05 was regarded as significant.

\section{RESULTS}

A total of 512 questionnaires were distributed of which 495 were returned, with a response rate of $96.39 \%$. Out of the 495 participants, $73.1 \%$ were females (Graph 1). About $78.2 \%$ students were in the age group between 19 and 24 years (Graph 2). The sample consisted of four groups according to the different academic levels: III year Bachelor of Dental Surgery (BDS; 30.5\%), IV year BDS $(29.5 \%)$, interns $(21 \%)$, and postgraduates $(19 \%$; Graph 3). About $19 \%$ of the students were pursuing Master of Dental Surgery (MDS) and majority (81\%) were pursuing BDS in the present study (Graph 4).

Table 1 describes the chi square results for the significant responses with respect to age, gender, academic levels, and educational qualification.

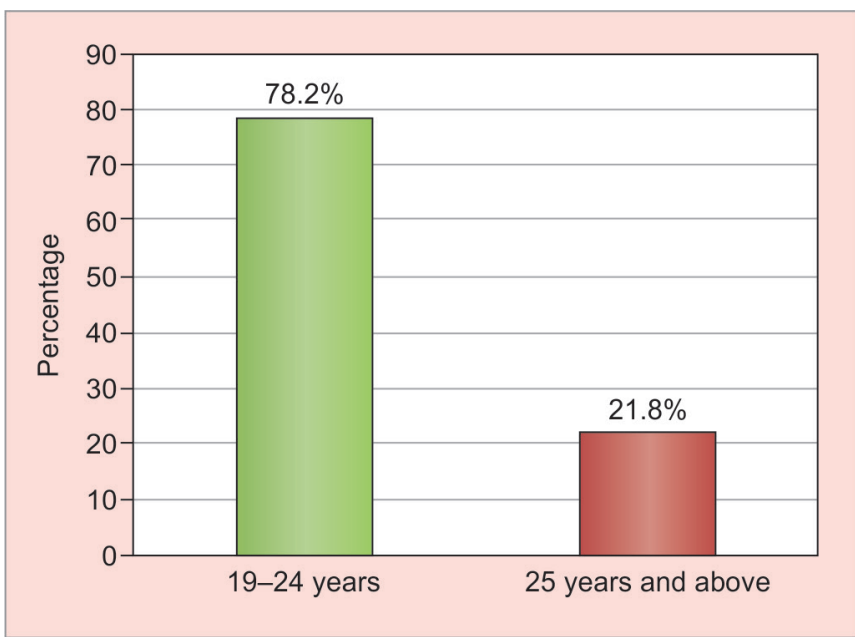

Graph 2: Percentage distribution of students based on their age 


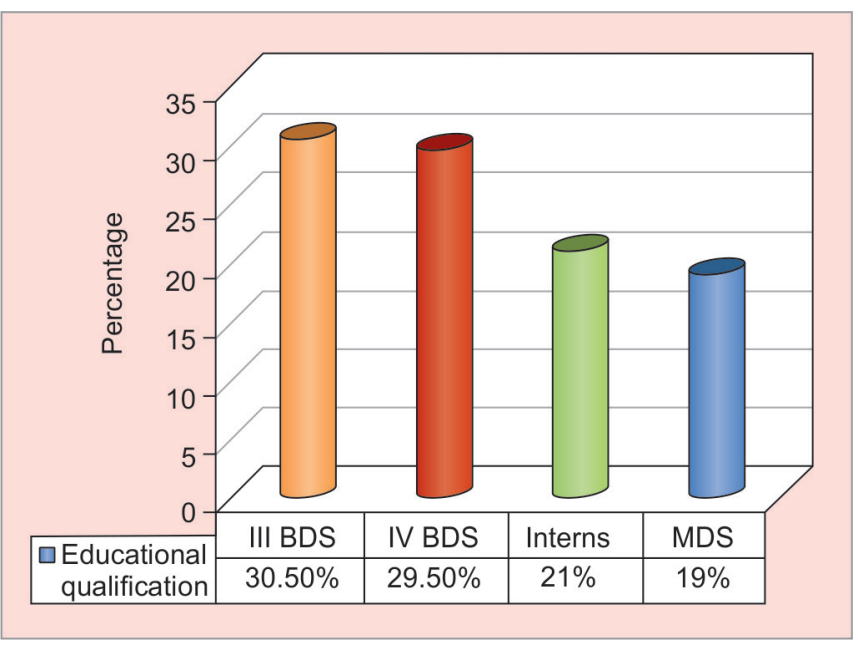

Graph 3: Percentage distribution of students based on their academic level

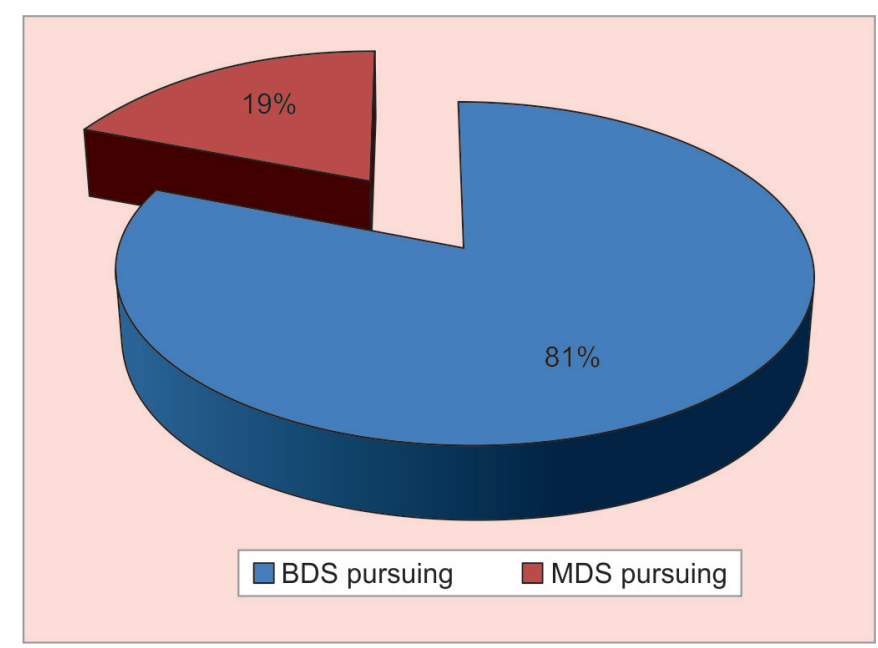

Graph 4: Percentage distribution of students based on their educational qualification

Table 1: Analysis of responses to knowledge, awareness, and attitude-based questions among students

\begin{tabular}{|c|c|c|c|c|}
\hline Questions & Responses & $n$ & $\%$ & Significance \\
\hline \multirow{4}{*}{$\begin{array}{l}\text { When you find someone } \\
\text { unresponsive in the middle of the } \\
\text { road, what will be your immediate } \\
\text { action? }\end{array}$} & (1) Open airway & 287 & 58 & \multirow[t]{4}{*}{$0.000^{\mathrm{b}}$ (age, class, education) } \\
\hline & (2) Start chest compression & 113 & 22.8 & \\
\hline & (3) Activate EMS & 81 & 16.4 & \\
\hline & (4) Give two breathings & 14 & 2.8 & \\
\hline \multirow{4}{*}{$\begin{array}{l}\text { What is the location of chest } \\
\text { compression in CPR? }\end{array}$} & (1) Left side of the chest & 168 & 33.9 & \multirow[t]{4}{*}{$0.000^{\mathrm{b}}$ (age, class, education) } \\
\hline & (2) Right side of the chest & 27 & 5.5 & \\
\hline & (3) Mid chest & 222 & 44.8 & \\
\hline & (4) Xiphisternum & 78 & 15.8 & \\
\hline \multirow{4}{*}{$\begin{array}{l}\text { Indicate the number of chest } \\
\text { compressions to be done in adult } \\
\text { during CPR? }\end{array}$} & (1) $30 / \mathrm{min}$ & 199 & 40.2 & \multirow[t]{4}{*}{$0.000^{\mathrm{b}}$ (age, class) $0.002^{\mathrm{b}}$ (education) } \\
\hline & (2) $50 / \mathrm{min}$ & 120 & 24.2 & \\
\hline & (3) $80 / \mathrm{min}$ & 61 & 12.3 & \\
\hline & (4) $100 / \mathrm{min}$ & 115 & 23.2 & \\
\hline \multirow{4}{*}{$\begin{array}{l}\text { Which maneuver can be used to } \\
\text { open the airway? }\end{array}$} & (1) Sweep finger in mouth & 49 & 9.9 & \multirow[t]{4}{*}{$0.000^{\mathrm{b}}$ (age, class, education) } \\
\hline & (2) Head tilt-chin lift & 332 & 67.1 & \\
\hline & (3) Chin tilt-head lift & 69 & 13.9 & \\
\hline & (4) Chest compression method & 45 & 9.1 & \\
\hline \multirow{2}{*}{$\begin{array}{l}\text { Have you heard of Heimlich } \\
\text { maneuver? }\end{array}$} & (1) Yes & 187 & 37.8 & \multirow[t]{2}{*}{$0.000^{\mathrm{b}}$ (age, class, education) } \\
\hline & (2) No & 308 & 62.2 & \\
\hline \multirow{4}{*}{$\begin{array}{l}\text { Check for pulse no more than } \\
\text { in medical emergency }\end{array}$} & (1) $5 \mathrm{sec}$ & 78 & 15.8 & \multirow[t]{4}{*}{$0.000^{\mathrm{b}}$ (age, class, education) } \\
\hline & (2) $10 \mathrm{sec}$ & 206 & 41.6 & \\
\hline & (3) $15 \mathrm{sec}$ & 172 & 34.7 & \\
\hline & (4) $20 \mathrm{sec}$ & 39 & 7.9 & \\
\hline \multirow{2}{*}{$\begin{array}{l}\text { Have you ever seen a BLS being } \\
\text { done? }\end{array}$} & (1) Yes & 36 & 7.3 & \multirow[t]{2}{*}{$0.000^{\mathrm{b}}$ (age, class, education) } \\
\hline & (2) No & 459 & 92.7 & \\
\hline \multirow[t]{2}{*}{ If yes, have you ever done a BLS? } & (1) Yes & 36 & 7.3 & \multirow[t]{2}{*}{$0.000^{\mathrm{b}}$ (age, class, education) } \\
\hline & (2) No & 459 & 92.7 & \\
\hline \multirow[t]{5}{*}{ If no, reason for reluctance? } & (1) Fear of causing further harm to patient & 149 & 30.1 & \multirow[t]{5}{*}{$0.000^{\mathrm{b}}$ (age, class, education) } \\
\hline & (2) Fear of being punished by law & 22 & 4.4 & \\
\hline & (3) Fear of taking responsibilities & 34 & 6.9 & \\
\hline & (4) Not aware of procedure & 254 & 51.3 & \\
\hline & (5) Yes & 36 & 7.3 & \\
\hline \multirow[t]{3}{*}{ The last attended BLS workshop? } & Within last 5 years & 114 & 23 & \multirow[t]{3}{*}{$0.000^{\mathrm{b}}$ (age, class, education) } \\
\hline & More than 5 years & 42 & 8.5 & \\
\hline & Never attended & 339 & 68.5 & \\
\hline
\end{tabular}

$\chi^{2}=$ Chi-square test, ${ }^{a} p \leq 0.05$ significant, ${ }^{b} p \leq 0.01$ highly significant 
Table 2: Binominal logistic analysis of responses among the participants with different educational qualification

\begin{tabular}{|c|c|c|c|c|c|c|}
\hline \multirow[b]{2}{*}{ Questions } & \multirow[b]{2}{*}{ Education } & \multirow{2}{*}{$\begin{array}{l}\text { Regression } \\
\text { coefficient }\end{array}$} & \multirow{2}{*}{$p$-value } & \multirow[b]{2}{*}{ Odds ratio } & \multicolumn{2}{|c|}{$95 \%$ confidence interval } \\
\hline & & & & & Lower & Upper \\
\hline \multirow{2}{*}{$\begin{array}{l}\text { When you find someone unresponsive in the middle } \\
\text { of the road, what will be your immediate action? }\end{array}$} & BDS & 1.268 & $0.000^{\mathrm{b}}$ & 0.144 & 1.030 & 1.507 \\
\hline & MDS & 0.313 & $0.001^{\mathrm{b}}$ & 0.144 & 0.122 & 0.503 \\
\hline \multirow[t]{2}{*}{ What is the location of chest compression in CPR? } & BDS & 1.563 & $0.000^{\mathrm{b}}$ & 0.255 & 1.259 & 1.867 \\
\hline & MDS & 0.724 & $0.000^{\mathrm{b}}$ & 0.255 & 0.481 & 0.967 \\
\hline \multirow{2}{*}{$\begin{array}{l}\text { Indicate the number of chest compressions to be } \\
\text { done in adult during CPR }\end{array}$} & BDS & 1.678 & $0.000^{\mathrm{b}}$ & 0.141 & 1.344 & 2.011 \\
\hline & MDS & 0.427 & $0.002^{\mathrm{b}}$ & 0.141 & 0.161 & 0.693 \\
\hline \multirow[t]{2}{*}{ Which maneuver can be used to open the airway? } & BDS & 2.455 & $0.000^{\mathrm{b}}$ & 0.103 & 2.246 & 2.664 \\
\hline & MDS & 0.196 & $0.022^{\mathrm{b}}$ & 0.103 & 0.362 & 0.029 \\
\hline \multirow[t]{2}{*}{ Have you heard of Heimlich maneuver? } & BDS & 2.37 & $0.000^{\mathrm{b}}$ & 0.473 & 2.197 & 2.438 \\
\hline & MDS & 0.584 & $0.000^{\mathrm{b}}$ & 0.473 & 0.681 & 0.488 \\
\hline \multirow{2}{*}{$\begin{array}{l}\text { Check for pulse no more than ___ in medical } \\
\text { emergency }\end{array}$} & BDS & 2.733 & $0.000^{\mathrm{b}}$ & 0.152 & 2.499 & 2.967 \\
\hline & MDS & 0.324 & $0.001^{\mathrm{b}}$ & 0.152 & 0.510 & 0.137 \\
\hline \multirow[t]{2}{*}{ Have you ever seen a BLS being done? } & BDS & 2.122 & $0.000^{\mathrm{b}}$ & 0.306 & 1.998 & 2.246 \\
\hline & MDS & 0.359 & $0.000^{\mathrm{b}}$ & 0.306 & 0.458 & 0.260 \\
\hline \multirow[t]{2}{*}{ The last attended BLS workshop? } & BDS & 3.153 & $0.000^{\mathrm{b}}$ & 0.274 & 2.925 & 3.382 \\
\hline & MDS & 0.587 & $0.000^{\mathrm{b}}$ & 0.274 & 0.770 & 0.405 \\
\hline
\end{tabular}

${ }^{a} p \leq 0.05$ significant, ${ }^{b} p \leq 0.01$ highly significant

More than half of students in the present study said that they will immediately open the airway if they find someone unresponsive in the middle of the road. According to $44.8 \%$ of students, the location for chest compression in CPR is midchest. According to $40.2 \%$ students, the number of chest compression to be done in adult during CPR is 30/min. Majority (67.1\%) in the present study said that they will do head tilt-chin lift maneuver to open the airway and majority of them had heard about Heimlich maneuver; $68.5 \%$ of students have never attended a BLS workshop. About $92.7 \%$ had not seen a BLS being done.

Tables 2 and 3 depict the regression values of the responses based on the qualification and academic level.

\section{DISCUSSION}

The BLS is a simple life-saving protocol following a medical emergency. It is an integral part of emergency resuscitative care that aims to retain sufficient ventilation and circulation until the cause of the arrest is detected and eliminated. The medical emergencies are not rare in dental practice, as about two-thirds of dentists faced at least one emergency during the 12-month study period. ${ }^{7}$ Dentistry is a health profession that should provide complete medical care and treat the whole patient rather than focusing on the oral cavity. In India, the undergraduate curriculum as proposed by the Dental Council of India includes medical emergency management under the subjects of general medicine and oral and maxillofacial surgery. ${ }^{10}$ Keeping this in mind, only III and IV years (clinical dental students), and interns along with postgraduate students of both the dental colleges in Davangere were included in the study.
In a study by Alotaibi et al, ${ }^{7}$ dental students and staff in King Saud University reported that almost all the participants (99.1\%) had attended previous BLS workshops, whereas the present study showed that most of the participants $(68.5 \%)$ had not attended previous BLS workshops. Around $92.7 \%$ participants have not seen and not been involved in any patient resuscitation experience. On the contrary, in a study conducted by Gupta $\mathrm{T}$ et al ${ }^{11}$ on dentists of Udupi and Mangalore in India, majority of participating dentists recalled having received training in management of medical emergencies as undergraduates. The reasons for this variation could be lack of BLS workshops in their surroundings.

In the present study, a large number of the respondents $(51.3 \%)$ were reluctant to perform CPR to a stranger because they are not aware of the procedure and about one-third of them $(30.1 \%)$ indicated that the reason for reluctance is being afraid of causing further harm to the patient, which is comparable to the responses of participants in a study by Alotaibi et al. ${ }^{7}$

Only $23.2 \%$ of the responders answered the rate of chest compression as 100/minute in adults and children in the present study when compared with $35 \%$ of the responders in a study by Chandrasekaran et al, ${ }^{12}$ with the study group comprising medical, dental, nursing students, and faculty in a city in Tamil Nadu. More than half of the participants $(55.2 \%)$ did not know that the right location of chest compression is the midchest in the present study, whereas $74 \%$ participants did not know the correct location of chest compression in a study by Chandrasekaran et al. ${ }^{12}$ The present study results demonstrated that $83.6 \%$ participants were not aware about 
Basic Life Support Knowledge, Awareness, and Attitude among Dental Students in Davangere City, Karnataka, India

Table 3: Multinomial logistic analysis of responses among the participants with different academic levels

\begin{tabular}{|c|c|c|c|c|c|}
\hline \multirow[b]{2}{*}{ Questions } & \multirow[b]{2}{*}{ Academic level } & \multirow[b]{2}{*}{$p$-value } & \multirow[b]{2}{*}{ Odds ratio } & \multicolumn{2}{|c|}{ 95\% confidence interval } \\
\hline & & & & Lower & Upper \\
\hline \multirow{4}{*}{$\begin{array}{l}\text { When you find someone unresponsive } \\
\text { in the middle of the road what will be } \\
\text { your immediate action? }\end{array}$} & III year & Reference & Reference & Reference & Reference \\
\hline & IV year & $0.000^{\mathrm{b}}$ & 1.344 & 1.440 & 6.102 \\
\hline & Interns & 0.271 & 0.245 & 0.097 & 0.433 \\
\hline & MDS & $0.000^{\mathrm{b}}$ & 21.12 & 3.245 & 4.420 \\
\hline \multirow{4}{*}{$\begin{array}{l}\text { What is the location of chest } \\
\text { compression in CPR? }\end{array}$} & III year & Reference & Reference & Reference & Reference \\
\hline & IV year & $0.006^{b}$ & 2.079 & 0.428 & 10.003 \\
\hline & Interns & $0.001^{\mathrm{b}}$ & 0.941 & 0.211 & 0.823 \\
\hline & MDS & $0.009^{b}$ & 0.783 & 0.056 & 0.283 \\
\hline \multirow{4}{*}{$\begin{array}{l}\text { Indicate the number of chest } \\
\text { compressions to be done in adult during } \\
\text { CPR }\end{array}$} & III year & Reference & Reference & Reference & Reference \\
\hline & IV year & $0.006^{b}$ & 0.901 & 0.901 & 3.885 \\
\hline & Interns & $0.024^{a}$ & 0.693 & 0.109 & 0.651 \\
\hline & MDS & 0.901 & 0.031 & 0.050 & 0.271 \\
\hline \multirow{4}{*}{$\begin{array}{l}\text { Which maneuver can be used to open } \\
\text { the airway? }\end{array}$} & III year & Reference & Reference & Reference & Reference \\
\hline & IV year & $0.000^{\mathrm{b}}$ & 3.761 & 0.029 & 0.580 \\
\hline & Interns & 0.423 & 0.693 & 0.136 & 5.113 \\
\hline & MDS & 1.000 & 0.000 & 0.238 & 14.614 \\
\hline \multirow{4}{*}{$\begin{array}{l}\text { Check for pulse no more than } \\
\text { in medical emergency }\end{array}$} & III year & Reference & Reference & Reference & Reference \\
\hline & IV year & $0.000^{\mathrm{b}}$ & 1.210 & 0.624 & 3.138 \\
\hline & Interns & 0.591 & 0.194 & 2.523 & 15.990 \\
\hline & MDS & $0.028^{a}$ & 1.041 & 0.556 & 6.918 \\
\hline \multirow{4}{*}{$\begin{array}{l}\text { The reason for lack of knowledge about } \\
\text { BLS }\end{array}$} & III year & Reference & Reference & Reference & Reference \\
\hline & IV year & $0.000^{\mathrm{b}}$ & 2.639 & 0.460 & 7.327 \\
\hline & Interns & $0.000^{\mathrm{b}}$ & 1.173 & 0.422 & 2.153 \\
\hline & MDS & 0.497 & 0.154 & 0.695 & 2.157 \\
\hline \multirow[t]{4}{*}{ The last attended BLS workshop } & III year & Reference & Reference & Reference & Reference \\
\hline & IV year & $0.000^{\mathrm{b}}$ & 0.049 & 0.025 & 0.131 \\
\hline & Interns & $0.000^{b}$ & 1.204 & 0.088 & 0.569 \\
\hline & MDS & $0.002^{b}$ & 1.497 & 0.250 & 1.280 \\
\hline
\end{tabular}

${ }^{a} p \leq 0.05$ significant, ${ }^{b} p \leq 0.01$ highly significant

the immediate action to be taken if they found someone unresponsive in the middle of the road, whereas $89 \%$ failed to insist on activating EMS immediately after confirming the unresponsiveness in an adult in a study by Chandrasekaran et al. ${ }^{12}$ The reasons for this could be multifactorial, either their lack of basic knowledge of BLS or ignorance or lack of confidence in answering this question. The present study revealed that $62.2 \%$ of the participants were not aware of Heimlich maneuver. Most of the participants in the present study $(67.1 \%)$ responded that they will do head tilt-chin lift maneuver to open the airway, whereas in a study by Baduni et $\mathrm{al}^{13}$ only one responder knew that airway in a victim of trauma on road traffic accident should be maintained by jaw thrust. The reasons for this could be increased awareness toward BLS skills.

In the present study, it was noted that IV year undergraduate clinical students had better knowledge and awareness compared with III year, interns, and postgraduate students of both the dental colleges (Table 3). This could be attributed to the fact that IV year students attended general medicine and surgery clinics in their previous academic year and the subject of oral and maxillofacial surgery is integrated in the IV year. The present study also highlights that the overall knowledge and awareness among BDS and MDS students is not satisfactory.

\section{STRENGTH AND LIMITATIONS}

The present study included both theoretical and practicalbased questions but the study was confined to two dental colleges in Davangere city, so generalization of results cannot be done.

Practical skills of BLS could not be assessed in the study.

\section{CONCLUSION}

Taken altogether, the present study demonstrated that there is a significant lack of knowledge, awareness, and attitude among postgraduate students compared with undergraduate students regarding BLS. This study emphasizes the fact that undergraduate courses in dentistry must be revised or regularly updated on the 
knowledge and skills regarding BLS along with practical courses.

\section{RECOMMENDATIONS}

- This study should be carried out in various other medical, dental, and paramedical institutions and the knowledge, awareness, and attitude toward BLS among the students and faculty should be assessed.

- The participation of educational institutions to improve the training of students and professionals for $\mathrm{CPR}$ and other medical emergencies that can occur in the dental office is necessary.

\section{REFERENCES}

1. Narayan DPR, Biradar SV, Reddy MT, Sujatha BK. Assessment of knowledge and attitude about basic life support among dental interns and postgraduate students in Bangalore city, India. World J Emerg Med 2015;6(2):118-122.

2. Ratha K, Panda S, Pradhan R. Evaluate the effectiveness of planned teaching programme regarding basic life support (BLS) among Intern (B.Sc Nursing) Student at Selected Nursing College, Bhubaneswar, Odisha. IOSR J Nurs Health Sci (IOSR-JNHS) 2014 Jan;3(1):16-19.

3. Alanazi A, Alsalmeh $\mathrm{M}$, Alsomali $\mathrm{O}$, Maged Almurshdi A, Alabdali A, Al-Sulami M. Poor basic life support awareness among medical and college of applied medical sciences students necessitates the need for improvement in standards of BLS Training and Assessment for Future Health Care Providers. Middle-East J Sci Res 2014;21(5):848-854.

4. Abbas A, Bukhari SI, Ahmad F. Knowledge of first aid and basic life support amongst medical students: a comparison between trained and untrained students. J Pak Med Assoc 2011 Jun;61(6):613-616.

5. Manikandan M, Appachi MS, Manickavasagam R, Srinathkumar TS. Awareness of basic life support among health care professionals and trainees in Tamil Nadu. Natl J Emerg Med 2012 Aug-Oct;1(1):55-60.

6. Almesned A, Almeman A, AlAboudi AA, Alotaibi AZ, Aldamegh MS. Basic life support knowledge of healthcare students and professionals in the Qassim University. Int J Health Sci 2014 Apr;8(2):141-149.

7. Alotaibi O, Alamri F, Almufleh L, Alsougi W. Basic life support: knowledge and attitude among dental students and Staff in the College of Dentistry, King Saud University. Saudi J Dent Res 2016 Jan;7(1):51-56.

8. Sudeep CB, Sequeira PS, Jain J, Jain V, Maliyil M. Awareness of basic life support among students and teaching faculty in a dental college in Coorg, Karnataka. Int Dent J Stud Res 2013 Jun-Nov; 2(1): 4-21.

9. Highlights of the 2015 American Heart Association Guidelines Update for CPR and ECC.

10. Reddy S, Doshi D, Reddy P, Kulkarni S, Reddy S. Awareness of basic life support among staff and students in a dental school. J Contemp Dent Pract 2013 May;14(3):511-517.

11. Gupta T, Shankar Aradhya M.R, Anup N. Preparedness for management of medical emergencies among dentists in Udupi and Mangalore, India. J Contemp Dent Pract. 2008;9(3): $1-10$

12. Chandrasekaran S, Kumar S, Bhat SA, Saravanakumar, Shabbir PM, Chandrasekaran V. Awareness of basic life support among medical, dental, nursing students and doctors. Indian J Anaesth 2010 Mar;54(2):121-126.

13. Baduni N, Prakash P, Srivastava D, Sanwal MK, Singh BP. Awareness of basic life support among dental practitioners. Natl J Maxillofac Surg 2014 Jan;5(1):19-22. 